\title{
Ionospheric characteristics of the dusk-side branch of the two-cell aurora
}

\author{
J.-H. Shue ${ }^{1}$, P. T. Newell ${ }^{2}$, K. Liou ${ }^{2}$, C.-I. Meng ${ }^{2}$, M. R. Hairston ${ }^{3}$, and F. J. Rich ${ }^{4}$ \\ ${ }^{1}$ Institute of Space Science and Dept. of Atmospheric Sciences, National Central University, Jhongli, Taoyuan 32001, Taiwan \\ ${ }^{2}$ The Johns Hopkins University Applied Physics Laboratory, 11100 Johns Hopkins Road, Laurel, MD 20723, USA \\ ${ }^{3}$ Center of Space Science, University of Texas in Dallas, POB 830688, Richardson, TX 75083, USA \\ ${ }^{4}$ Air Force Research Laboratory/VSBXP, 29 Randolph Road, Hanscom AFB, MA 01731, USA
}

Received: 6 September 2004 - Revised: 28 December 2005 - Accepted: 3 January 2006 - Published: 7 March 2006

\begin{abstract}
The two-cell aurora is characterized by azimuthally elongated regions of enhanced auroral brightness over extended local times in the dawn and dusk sectors. Its association with the convection, particle precipitation, and field-aligned currents under various phases of substorms has not been fully understood. With Polar Ultraviolet Imager auroral images in conjunction with Defense Meteorological Satellite Program (DMSP) F12 spacecraft on the dusk-side branch of the two-cell aurora, we are able to investigate an association of the auroral emissions with the electric fields, field-aligned currents, and energy flux of electrons. Results show that the substorm expansion onset does not significantly change the orientation of the dusk-side branch of the two-cell aurora. Also, the orientation of the magnetic deflection vector produced by the region 1 field-aligned current changed from $73 \pm 1^{\circ}$ to the DMSP trajectory during the substorm growth phase, to $44 \pm 6^{\circ}$ to the DMSP trajectory during the substorm expansion phase. With a comparison between the orientation of the dusk-side branch of the two-cell aurora and the orientation of the magnetic deflection vector, it is found that the angular difference between the two orientations is $28 \pm 5^{\circ}$ during the substorm growth phase, and $13 \pm 6^{\circ}$ during the substorm expansion phase.
\end{abstract}

Keywords. Ionosphere (Auroral ionosphere; Electric fields and currents; Particle precipitation)

\section{Introduction}

The coupling between the solar wind, magnetosphere, and ionosphere is an important subject in the field of solarterrestrial physics. Dungey (1961) postulated an open magnetosphere in which the southward interplanetary magnetic

Correspondence to: J.-H. Shue

(jhshue@jupiter.ss.ncu.edu.tw) field (IMF) merges with the Earth's dipole magnetic field. One part of the solar wind energy directly transfers into the ionosphere. Some of the other part of the solar wind energy is stored in the magnetotail and released into the ionosphere during the substorm expansion phase. The ionospheric electric fields are changed in response to the two types of energy transfer.

Auroral electrojets are determined by both the electric field and conductance in the ionosphere. The electrojet system can be separated into two categories according to signatures determined with data from ground-based magnetometer stations. These two categories are commonly denoted as disturbance polar of the first type $(D P 1)$ and disturbance polar of the second type (DP 2) (Nishida, 1968). The DP 1 system, which is centered near midnight, increases its strength suddenly at the onset of the substorm expansion (Clauer and Kamide, 1985). The DP 2 system, which is centered in the dusk and dawn sectors, changes its strength in the growth phase of a substorm. The $D P 1$ system represents the loading-unloading process, while the $D P 2$ system represents the direct-driven process in the solar wind-magnetosphere coupling. The former is related to a sudden energy release, which is also denoted as the substorm electrojet. The latter is associated with a convection enhancement caused by a southward IMF, which is also denoted as the convection electrojet. The relative importance of the convection and substorm electrojets to the electric field and conductance depends on the locations of the electrojets and the phase of substorms (Kamide, 1982; Kamide and Kokubun, 1996).

As stated above, the auroral electrojets have a twocomponent feature. It is interesting to ask whether aurora also has a two-component feature because the aurora is influenced by the solar wind-magnetosphere-ionosphere interactions. With Polar Ultraviolet Imager (UVI) auroral images, Shue et al. (2002) showed that the auroral dynamics 


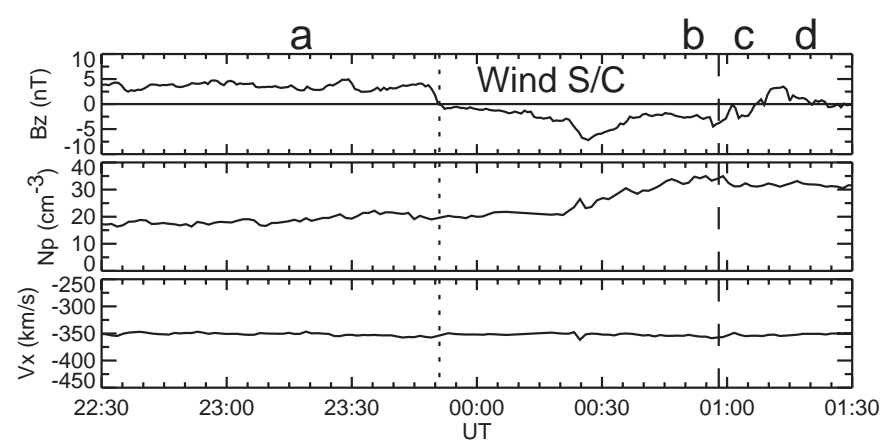

\section{Polar UVI}
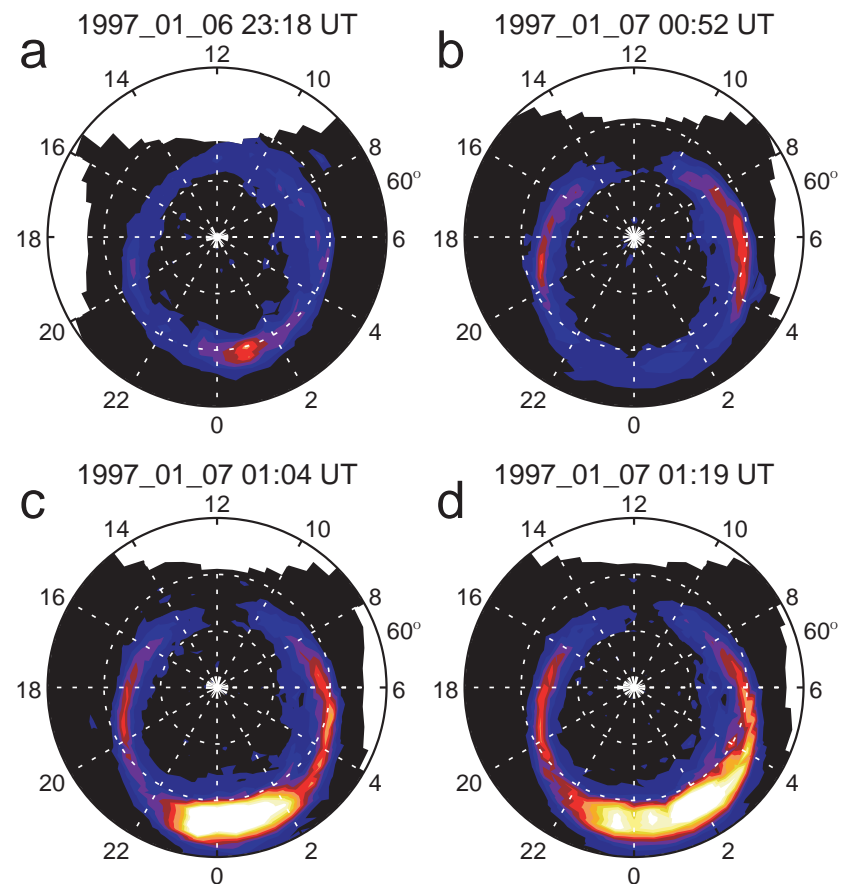

Photons $/ \mathrm{cm}^{2}-\mathrm{s}$

$\begin{array}{lllllllllll}0.0 & 2.0 & 4.0 & 6.0 & 8.0 & 10.0 & 12.0 & 14.0 & 16.0 & 18.0 & 20.0\end{array}$

Fig. 1. A demonstration of two-component auroras, the two-cell aurora and the substorm aurora. (a) Auroral activity was weak. (b) The two-cell aurora became prominent as southward IMF sustained. (c) A substorm added an additional auroral feature to the nightside. (d) The substorm continuously increased its strength. The corresponding solar wind conditions for the four images are shown in the solar wind measurements from the Wind spacecraft, which are labeled in a-d. The vertical dotted (dashed) line in the solar wind measurements denotes the southward IMF turning (the substorm expansion onset) (From Shue et al., 2002).

for a substorm shows a two-component feature. Figure 1 is a demonstration of the two-component feature of aurora. The Wind spacecraft observed a northward IMF followed by a southward IMF during the event. Auroral activity was weak (Fig. 1a) when the IMF was northward. An auroral feature, which is called the two-cell aurora, appeared in the dusk and dawn sectors in response to the southward IMF. The characteristic of the two-cell aurora is azimuthally elongated over extended local times with gaps at noon and midnight (Fig. 1b). A substorm occurred near midnight at 00:57 UT, adding an additional aurora in the midnight sector (Fig. 1c). The substorm continuously increased its strength (Fig. 1d).
The two-cell convection pattern is typical for southward IMF (Heppner and Maynard, 1987). This pattern is consistent with upward region 1 field-aligned currents at higher latitudes and downward region 2 field-aligned currents at lower latitudes on the dusk side, and downward region 1 fieldaligned currents at higher latitudes and upward region 2 at lower latitudes on the dawn side (Iijima and Potemra, 1976). The upward field-aligned currents may produce strong electron precipitation into the ionosphere and hence intense aurora. The resultant auroral pattern will have one branch at higher latitudes on the dusk side and the other at lower latitudes on the dawn side. 
Shue et al. (2000) reexamined five events of the intense growth phase preceding the substorm expansion phase, using data from ground-based magnetometer stations and auroral images from Viking or Polar spacecraft. They found that the locations of the stations in which observed large magnetic disturbances systematically matched the enhanced auroral emissions were in the morning sector, that is, the dawnside branch of the two-cell aurora, during the growth phase. These magnetic disturbances are large enough to be equivalent to weak to moderate substorms, and could be misidentified as a substorm expansion onset, if one is not aware of the existence of the intense growth phase events.

Relationships between convection electric fields, fieldaligned currents, particle precipitation, and auroral emissions have been extensively studied over the past decades (e.g. Meng, 1978; Heelis et al., 1980; Smiddy et al., 1980; Marklund et al., 1988). Our current understanding of the relationships based on previous studies are generalized below: discrete auroras are associated with upward field-aligned currents; peak auroral emissions match peak energy fluxes of precipitating electrons; and convection reversals lie in the region 1 field-aligned currents, which connect to the lowlatitude boundary layer. Nonetheless, ionospheric characteristics associated with the two-cell aurora have not been fully understood, for example, the dependence of the magnetic deflection vector produced by the field-aligned currents under various phases of the substorms.

The goal of this study is to investigate characteristics of associated convection, precipitation, and field-aligned currents with the two-cell aurora using Defense Meteorological Satellite Program (DMSP) ion drift meter, particle, and magnetometer data. The five intense growth phase events studied by Shue et al. (2000) did not develop into full-scale substorms. A comprehensive study of the two-cell aurora is important for understanding the cause of the intense growth phase, energy transport in the magnetosphere and ionosphere system for the growth phase, and a linkage to the development of substorms.

\section{Data}

The Polar Ultraviolet Imager (UVI) instrument consists of four major optical filters with different wavelengths at $\sim 130.4 \mathrm{~nm}$ and $\sim 135.6 \mathrm{~nm}$ for atomic oxygen lines, and at $\sim 150.0 \mathrm{~nm}$ (Lyman-Birge-Hopfield short or LBH-short) and $\sim 170.0 \mathrm{~nm}$ (Lyman-Birge-Hopfield long or LBH-long) for molecular and atomic nitrogen lines (Torr et al., 1995). It is generally believed that the auroral emission from the LBHlong band is proportional to the electron energy flux (Strickland et al., 1993; Germany et al., 1994). Hard electrons penetrate deeper into the lower ionosphere where there is a higher abundance of $\mathrm{O}_{2}$, leading to stronger absorption in the LBHshort band. This results in a higher ratio of the LBH-long band to the LBH-short band for the hard electrons. To avoid the absorption problem in the LBH-short band, we used auroral images from the LBH-long band to identify the two-cell aurora. The LBH-long band can be easily compared with the energy flux of electrons measured by DMSP.

A series of calibrations were performed to subtract background emissions, convert counts to photon fluxes, correct flat field and nadir-looking platform effects, and subtract dayglow emissions from the images (Brittnacher et al., 1997; Liou et al., 1998). A geomagnetic coordinate system of the Altitude Adjusted Corrected Geomagnetic Model (AACGM) (Baker and Wing, 1989) was used to calculate magnetic local time (MLT) and magnetic latitude (MLAT) for each pixel of the images. Pixels of these images were resampled into a uniform grid system of $0.5 \mathrm{~h}$ in MLT and $1^{\circ}$ in MLAT. The uncertainty defined as the standard deviation of the mean was also estimated at the time we calculated the mean for each grid.

Shue et al. (2002) identified 82 periods of the two-cell aurora using UVI images obtained from January 1997 to August 1998, most of which were followed by substorm expansions. Because of scarce conjunctions with DMSP F12 passes, only nine events have available DMSP particle precipitation, plasma flow, and magnetic field data. The date and time duration of the nine events are listed in Table 1.

The DMSP F12 spacecraft is in a nearly circular, Sunsynchronous orbit at $\sim 847-\mathrm{km}$ altitude with an orbital period of $101 \mathrm{~min}$. The onboard SSJ/4 special sensor precipitating electron and ion spectrometer measures the energy flux and energy of precipitating electrons and ions in the range of $32 \mathrm{eV}$ to $30 \mathrm{keV}$ (Hardy et al., 1984). The spectrometer has narrow apertures looking toward the local zenith. The spatial resolution of the spectrometer is $\sim 7 \mathrm{~km}$.

The onboard Special Sensor Magnetometer (SSM) measures magnetic fields (Rich et al., 1985). We need to adjust the baseline of the magnetometer data. The problem is that the sensor is body-mounted and it measures both the fieldaligned currents and currents in the spacecraft power system. An average of magnetic disturbances between $60-65^{\circ}$ and $75-80^{\circ}$ was used for the baseline. For the original coordinate system of the SSM sensor, the $+X$ component of the measured magnetic field is down along the local vertical direction. The $+Y$ component of the measured field is perpendicular to $+X$ and in the forward direction. Since the spacecraft's velocity vector is not exactly perpendicular to the local vertical direction at all times, there is a very small angle between the $+Y$ direction and the spacecraft's velocity vector. The $+Z$ component of the measured field is perpendicular to $+X$ and $+Y$ in the sense of a right-handed coordinate system. Thus, $+Z$ is toward the nightside of the orbit and is the best component to represent field-aligned currents.

The DMSP spacecraft has a Special Sensor for Ions, Electrons, and Scintillation (SSIES) plasma instrument array on board to measure the in-situ plasma environment. The SSIES array includes an ion drift meter (IDM), which measures the ion velocities perpendicular to the direction of the spacecraft's motion (Rich and Hairston, 1994). Since the periods of this study were toward the end of the solar minimum, the winter polar regions were low in ion density. Under these conditions the SSIES instrument provided sparse data. Like 
Table 1. Study events used.

\begin{tabular}{cccccccc}
\hline $\begin{array}{c}\text { Event } \\
\text { No. }\end{array}$ & Date & Time Interval & $\begin{array}{c}T_{a} \\
(\mathrm{~min})\end{array}$ & $\begin{array}{c}\text { Substorm } \\
\text { Phase }\end{array}$ & $\begin{array}{c}\phi_{m} \\
\text { (degree) }\end{array}$ & $\begin{array}{c}\phi_{t} \\
\text { (degree) }\end{array}$ & $\begin{array}{c}\left|\phi_{m}-\phi_{t}\right| \\
(\text { degree })\end{array}$ \\
\hline 01 & 18 Jan 1997 & 01:00-01:05 UT & -72 & Growth & 69 & 49 & 20 \\
02 & 18 Jan 1997 & 02:41-02:47 UT & +30 & Expansion & 36 & 40 & 04 \\
03 & 26 Jan 1997 & 01:04-01:12 UT & -68 & Growth & 74 & 33 & 41 \\
04 & 26 Jan 1997 & 02:45-02:53 UT & +33 & Expansion & 50 & 49 & 01 \\
05 & 31 Jan 1997 & 01:44-01:50 UT & -15 & Growth & 76 & 49 & 27 \\
06 & 6 Feb 1997 & 03:55-04:02 UT & +08 & Expansion & 25 & 56 & 31 \\
07 & 1 Jul 1997 & $01: 31-01: 38$ UT & -05 & Growth & 74 & 51 & 23 \\
08 & 24 Jul 1997 & 13:53-13:59 UT & +01 & Expansion & 51 & 41 & 10 \\
09 & 6 Aug 1997 & 02:39-02:47 UT & +09 & Expansion & 60 & 40 & 20 \\
\hline
\end{tabular}

$T_{a}$ : Timing away from the expansion onset. Negative (Positive) means before (after) the onset.

$\phi_{m}$ : The orientation of the magnetic deflection vector deviated from the DMSP trajectory.

$\phi_{t}$ : The orientation of the two-cell aurora deviated from the DMSP trajectory.

magnetometer data, drift meter data have a baseline problem. The baseline is affected on the nightside by low total ion density and the presence of $\mathrm{H}^{+}$at mid-latitudes and by low total ion density on the dayside. The best way to adjust the baseline is to subtract a straight line that connects between a point on the dusk side and a point on the dawn side (e.g. Shue and Weimer, 1994). However, data gaps do not enable us to do this straight line subtraction. Instead, we subtracted a constant value that was obtained from an average of electric fields over $50-55^{\circ}$. The coordinate system of IDM is different from that of SSM. The $+X$ component is parallel to the spacecraft velocity vector. The $+Z$ component is vertical away from the center of the Earth. The $+Y$ component of the measured field is perpendicular to $+X$ and $+Z$ in the sense of a right-handed coordinate system. Thus, $+Y$ is toward the dayside of the orbit plane.

All DMSP measurements were transformed into the following coordinate system such that the $+X$ component is in the direction of the spacecraft velocity vector, the $+Y$ component is perpendicular to the $+X$ component and points toward the nightside of the orbit plane, and the $+Z$ component follows a right-handed rule.

\section{Results}

For demonstration purposes we will show four events which best represent the characteristics of the two-cell aurora. The first one is the 01:44-01:50 UT, 31 January 1997 event. We selected two consecutive LBH-long images at 01:46 and 01:49 UT which were closest to the period of this event, as shown in Fig. 2a. The images show the typical two-cell auroral feature. The white line on each image denotes the trajectory of the DMSP F12 spacecraft during the event, moving from the equatorward side of the aurora to the poleward side. The two ends of the line denote the locations of DMSP at the beginning and the end of the event. The orientation of the two-cell aurora determined by the tangent to the locus of the maximum emission as one moves azimuthally along the region of auroral emissions was at an angle of $\sim 49^{\circ}$ to the DMSP trajectory.

The $+Y$ component of the magnetic field points toward the nightside of the orbit plane. The magnetic field disturbance equatorward of the auroral oval was almost zero, as shown in the black line in the $B_{y} / B_{x}$ panel of Fig. 2b. This magnetic field disturbance increased and then decreased significantly. Near the two-cell aurora, the magnetic field pattern shows a double sheet of field-aligned currents. A horizontal white (shaded) bar denotes the main upward region 1 (downward region 2) field-aligned current which we identified. It should be noted that we ignored some small-scale field-aligned currents which were embedded in the main field-aligned currents. The $X$ component of the magnetic field $\left(B_{x}\right)$ was small during the period, as shown in the blue line in the $B_{y} / B_{x}$ panel. The orientation of the magnetic deflection vector was estimated to be at an angle of $\sim 76^{\circ}$ to the DMSP trajectory. It results in a $27^{\circ}$ difference between the orientations of the magnetic deflection vector and the two-cell aurora.

The $V_{y}$ panel shows that the convection reversal lay in the upward region 1 field-aligned current, which is consistent with results of previous studies. The convection was antisunward in the polar cap and returned sunward at lower latitudes on the dusk. This convection feature is consistent with the dusk-side portion of the typical two-cell convection pattern.

In this study we calibrated the peak DMSP electron energy flux with the peak auroral emission along the spacecraft's trajectory because the location of the peak auroral emission is least affected by a wobble effect on the UVI images and sensitivity thresholds of the UVI instrument. Note that the wobble effect and sensitivity thresholds may introduce some uncertainty as to an identification of auroral boundaries, if we use a threshold (Brittnacher et al., 1999; Baker et al., 2000; Shue et al., 2001) or a ratio (Kauristie et al., 1999; Baker et al., 2000; Carbary et al., 2003) method. 
a) Polar UVI
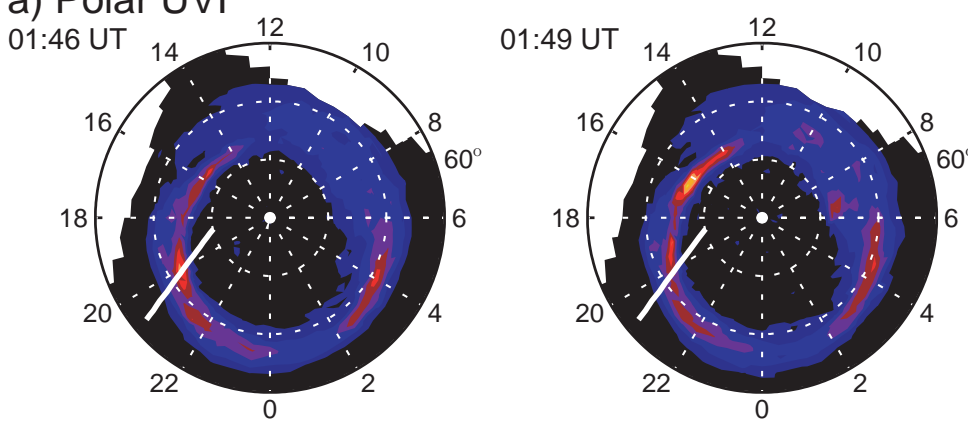

Photons $\mathrm{cm}^{-2} \mathrm{~s}^{-1}$

\begin{tabular}{|r|}
\hline 20.0 \\
18.0 \\
16.0 \\
14.0 \\
12.0 \\
10.0 \\
8.0 \\
6.0 \\
4.0 \\
2.0 \\
0.0
\end{tabular}

b) DMSP SSIES and SSM

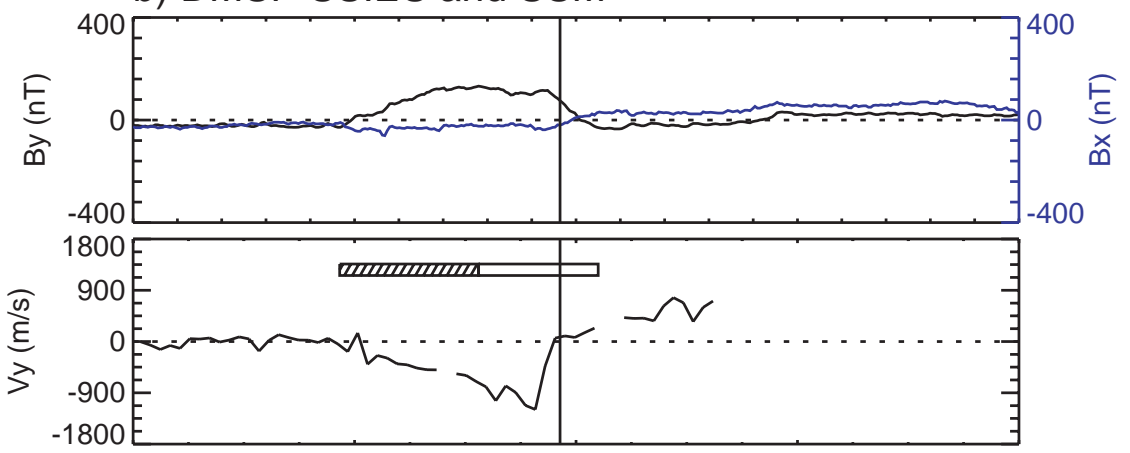

F12 c) DMSP SSJ4

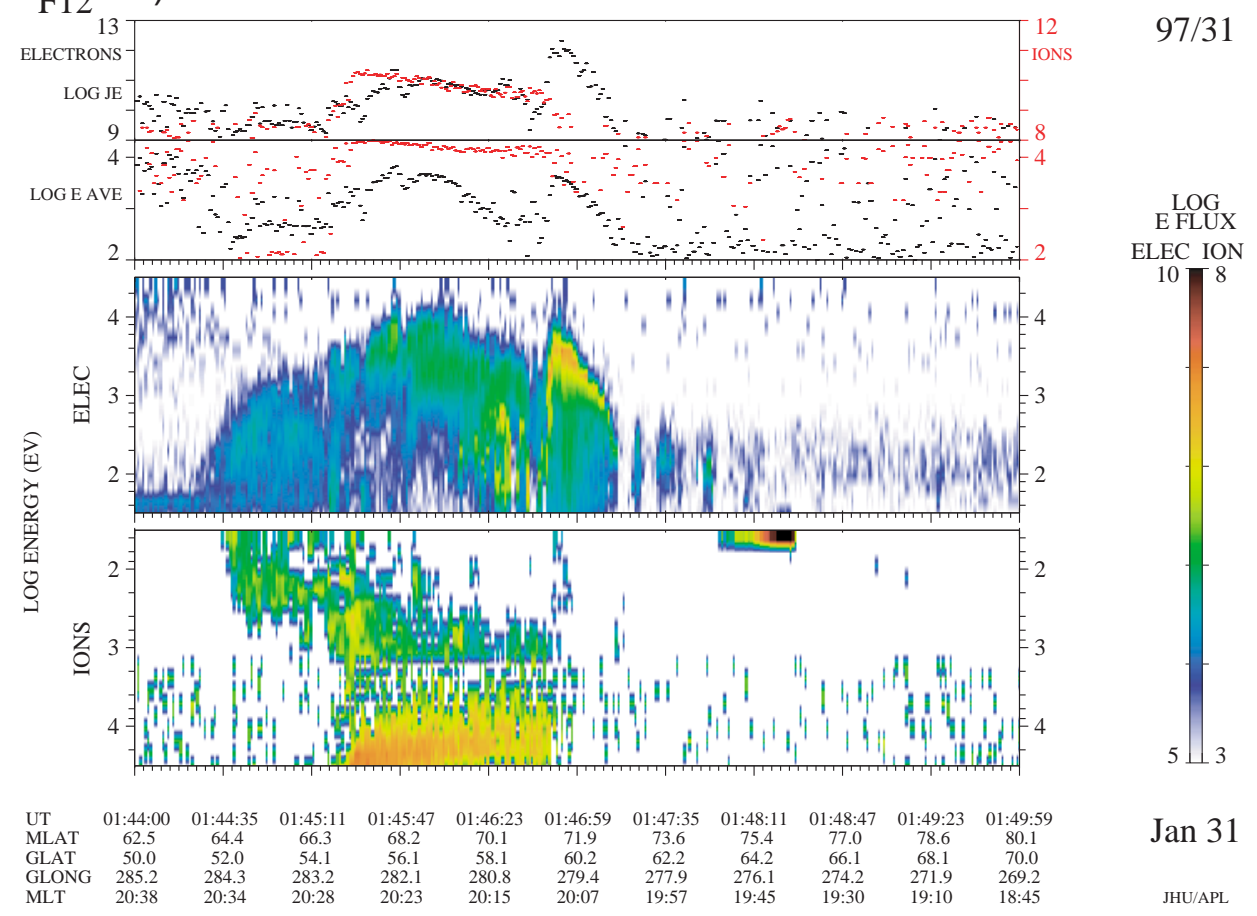

Fig. 2. A summary of observations for the 01:44-01:50 UT, 31 January 1997 event. (a) We selected two consecutive Polar UVI LBH-long auroral images which were closest to the period of the event. The white line on each image marks the trajectory of the DMSP F12 spacecraft, moving from the equatorside of the aurora to the poleward side. The both ends of the line denote the locations of DMSP at the beginning and the end of the event. (b) The black (blue) curve in the magnetic field panel represents variations of the $Y$ and $X$ components of the magnetic field produced by field-aligned currents. The vertical line in the $B_{y} / B_{x}$ and convection $\left(V_{y}\right)$ panels denotes the location of the peak energy flux determined from (c) the DMSP electron energy flux data. The white (shaded) horizontal bar in the $V_{y}$ panel represents the interval of large-scale region 1 (region 2) field-aligned currents. Note that the $+X$ component is in the direction of the spacecraft velocity vector. The $+Y$ component is perpendicular to the $+X$ component and points toward the nightside of the orbit plane. 
a) Polar UVI

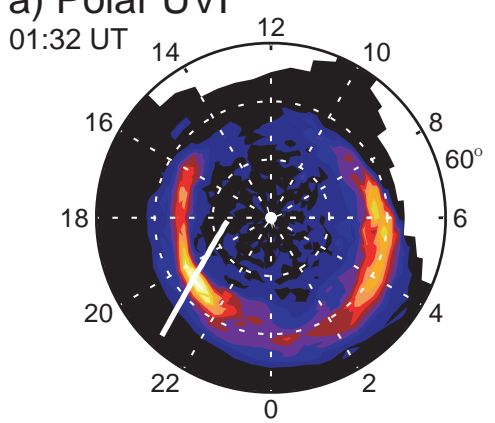

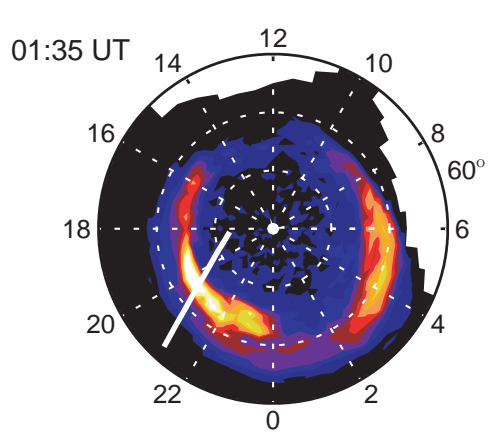

Photons $\mathrm{cm}^{-2} \mathrm{~s}^{-1}$

\begin{tabular}{|r}
25.0 \\
22.5 \\
20.0 \\
17.5 \\
15.0 \\
12.5 \\
10.0 \\
7.5 \\
5.0 \\
2.5 \\
0.0
\end{tabular}

b) DMSP SSIES and SSM
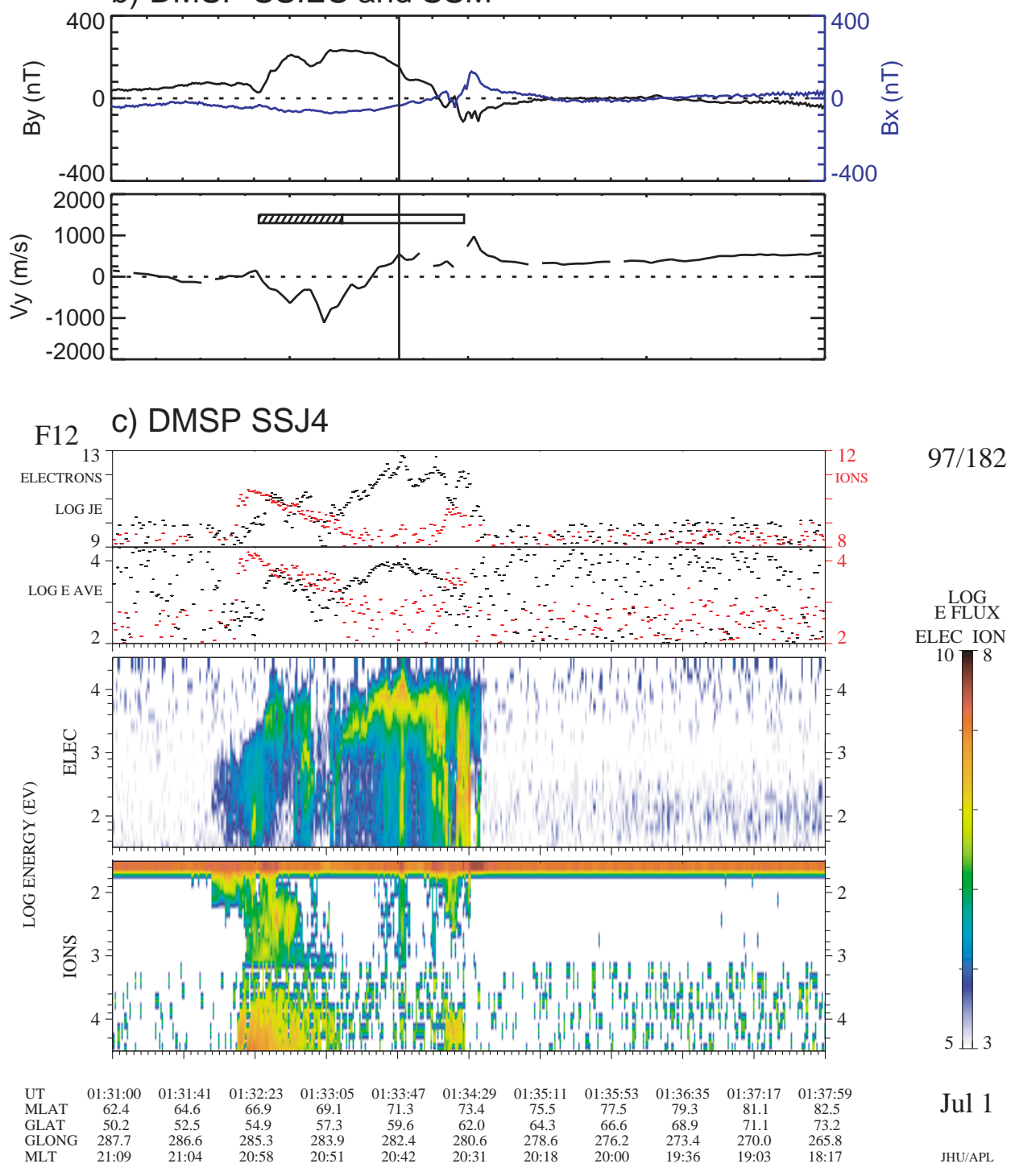

Fig. 3. A summary of observations for the 01:31-01:38 UT, 1 July 1997 event. The format is the same as that for Fig. 2.

The electron energy flux reached its maximum value at 01:46:53 UT, as shown in Fig. 2c. The vertical line in the panel of $B_{y} / B_{x}$ and $V_{y}$ denotes the location of this maximum value. The spectrogram displays an inverted-V discrete elec- tron structure (Lin and Hoffman, 1979; Newell et al., 1996), occurring in the region 1 field-aligned current. Since the auroral emission from LBH-long is proportional to the electron energy flux, the peak LBH-long and peak electron energy 
a) Polar UVI
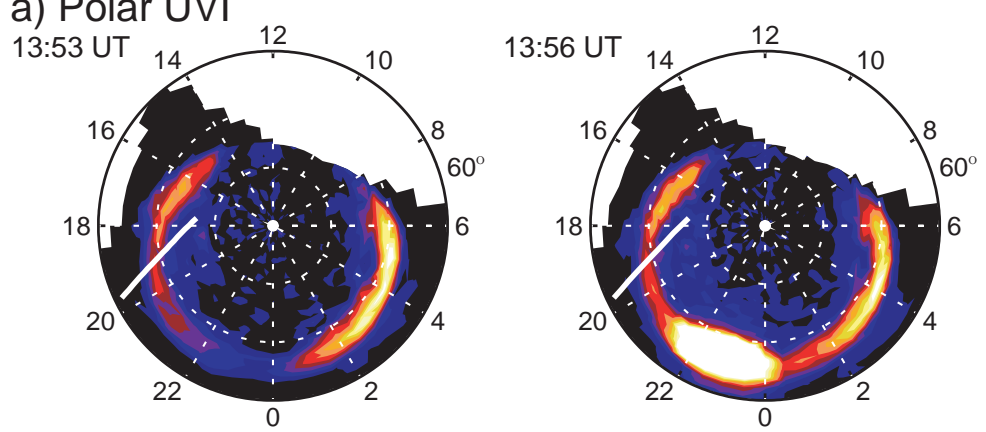

Photons $\mathrm{cm}^{-2} \mathrm{~s}^{-1}$

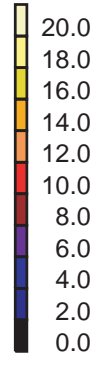

b) DMSP SSIES and SSM

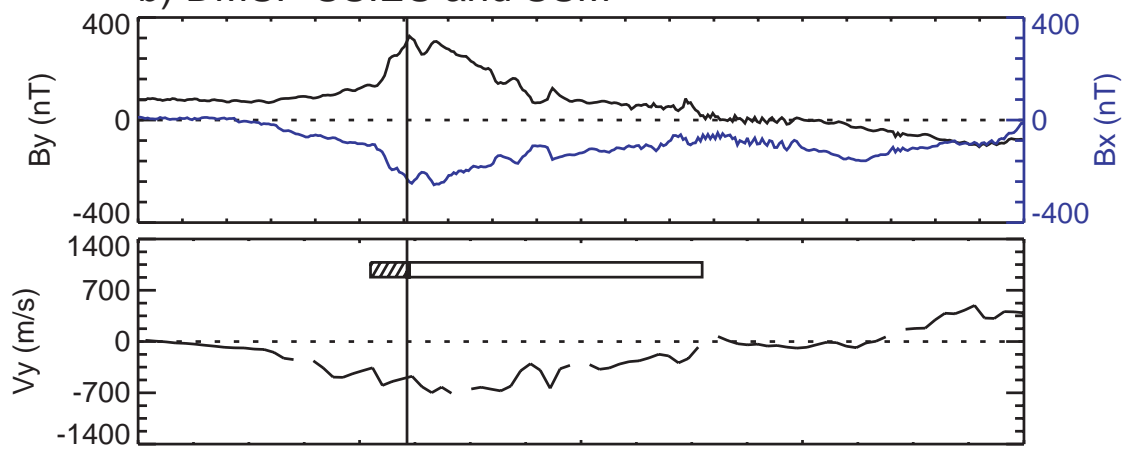

\section{F12 c) DMSP SSJ4}

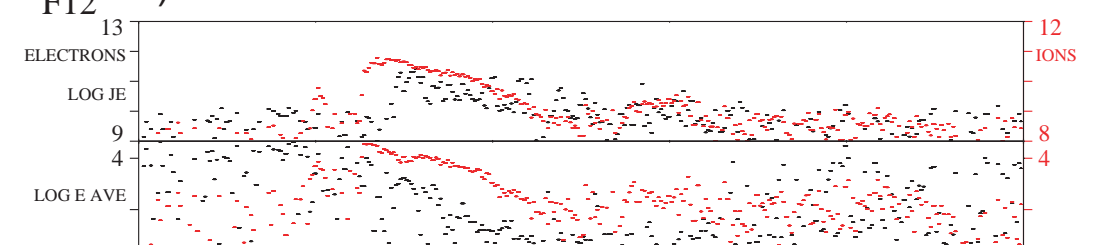

$97 / 205$

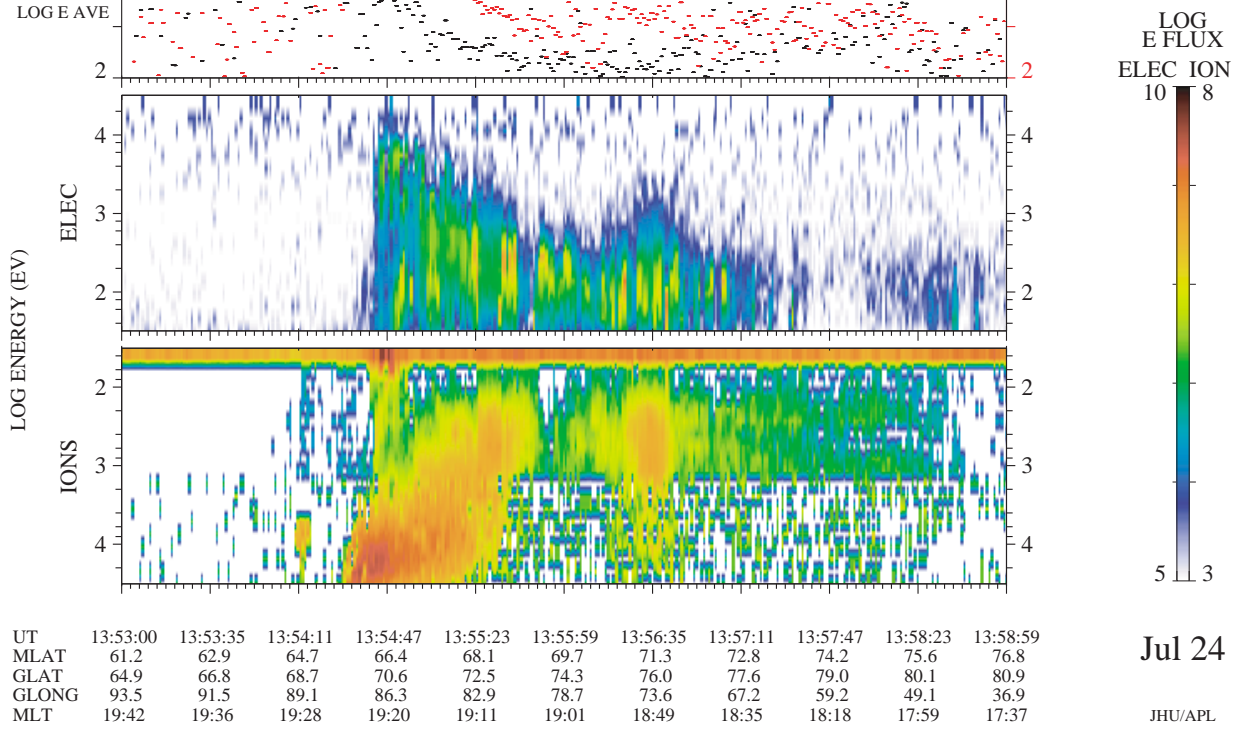

$\begin{array}{lccccccccccc}\text { UT } & 13: 53: 00 & 13: 53: 35 & 13: 54: 11 & 13: 54: 47 & 13: 55: 23 & 13: 55: 59 & 13: 56: 35 & 13: 57: 11 & 13: 57: 47 & 13: 58: 23 & 13: 58: 59 \\ \text { MLAT } & 61.2 & 62.9 & 64.7 & 66.4 & 68.1 & 69.7 & 71.3 & 72.8 & 74.2 & 75.6 & 76.8 \\ \text { GLAT } & 64.9 & 66.8 & 68.7 & 70.6 & 72.5 & 74.3 & 76.0 & 77.6 & 79.0 & 80.1 & 80.9 \\ \text { GLONG } & 93.5 & 91.5 & 89.1 & 86.3 & 82.9 & 78.7 & 73.6 & 67.2 & 59.2 & 49.1 & 36.9 \\ \text { MLT } & 19: 42 & 19: 36 & 19: 28 & 19: 20 & 19: 11 & 19: 01 & 18: 49 & 18: 35 & 18: 18 & 17: 59 & 17: 37\end{array}$

Jul 24

Fig. 4. A summary of observations for the 13:53-13:59 UT, 24 July 1997 event. The format is the same as that for Fig. 2.

should be colocated. Thus, this indicates that the dusk-side branch of the two-cell aurora is discrete.

The second event is for 01:31-01:38 UT, 1 July 1997. The auroral intensity for this event was higher than the previous event. The two closest LBH-long images to the period of the event were chosen, as shown in Fig. 3a. The DMSP spacecraft traversed the dusk-side branch of the two-cell aurora at an angle of $\sim 51^{\circ}$ from the equatorward side of the auroral 
oval during the event. Although there were several smallscale field-aligned currents shown in the $B_{y}$ panel of Fig. 3b, we identified only the main ones, as shown in the horizontal white and shaded bars for the upward region 1 and downward region 2 field-aligned currents, respectively. $B_{x}$ was small compared to $B_{y}$. The orientation of the magnetic deflection vector was found to deviate at an angle of $\sim 74^{\circ}$ to the DMSP trajectory line. The orientations of the magnetic deflection vector and the two-cell aurora have a $23^{\circ}$ difference.

The $V_{y}$ panel of Fig. $3 \mathrm{~b}$ shows the ionospheric convection for the 1 July 1997 event. The convection was anti-sunward in the polar cap and returned sunward at lower latitudes on the dusk side. This convection feature is consistent with the dusk-side portion of the typical two-cell convection pattern. The convection reversal lay in the region 1 field-aligned current.

The previous event shows a single inverted- $\mathrm{V}$ electron structure which was associated with the upward region 1 field-aligned current. However, in this event, there exists several discrete electron structures, as shown in Fig. 3c, which are consistent with several up-and-down changes in the magnetic field disturbances. We selected the largest one to compare to the main regions of the field-aligned currents. It shows that the maximum precipitating electron flux occurred in the region 1 field-aligned current.

The third one is the 13:53-13:59 UT, 24 July 1997 event. We selected two consecutive LBH-long images at 13:53 and 13:56 UT for this period, as shown in Fig. 4a. The images show that the typical two-cell auroral feature occurred at 13:53 UT and a substorm occurred at pre-midnight at 13:56 UT. The white lines on the images denote the trajectory of DMSP during the event, moving from the equatorward side of the aurora to the poleward side at an angle of $\sim 41^{\circ}$ against the orientation of the two-cell aurora. The images show a transition from the growth phase to the substorm expansion phase. In this case the convection reversal lay in the region 1 field-aligned current, as shown in Fig. 4b. Data gaps for electric fields over $50-65^{\circ}$ may introduce an error in baseline removing. In this event we removed the baseline using an average of the electric fields over $65-66^{\circ}$.

In this event there were several local energy flux peaks in the upward field-aligned currents, as shown in Fig. 4c. The largest peak is located at the region 1 field-aligned current. In this substorm transition event, $B_{x}$ was significantly large comparing to $B_{y}$. It is apparent that $B_{x}$ and $B_{y}$ were anticorrelated. The orientation of the magnetic deflection vector is estimated to be $\sim 51^{\circ}$ to the DMSP trajectory. The difference between the orientations of the magnetic deflection vector and the two-cell aurora is $10^{\circ}$.

The substorm aurora fully developed during the fourth event (02:41-02:47 UT, 18 January 1997), as shown in Fig. 5a. Note that the two-cell aurora occurred prior to the substorm expansion onset (not shown). The DMSP F12 spacecraft moved from the equatorward side of the aurora to the poleward side, traversing the two-cell aurora at an angle of $\sim 40^{\circ}$. We selected two consecutive LBH-long images which were closest to the period of the event. The auroral images show that the substorm bulge reached the trajectory of DMSP.

The convection reversal lay in the upward region 1 fieldaligned current, as shown in Fig. 5b. The antisunward convection appears in the polar cap and the sunward convection appears at lower latitudes on the dusk side. This feature is consistent with the dusk-side portion of the typical two-cell convection pattern. The main large-scale region 1 and 2 fieldaligned currents were identified and marked as the white and shaded horizontal bars, respectively.

Figure $5 \mathrm{c}$ shows that the electron energy flux had a significant increase in the upward region 1 field-aligned currents, which was associated with the electron acceleration in the high altitude. As in the 24 July 1997 event, $B_{x}$ and $B_{y}$ are anti-correlated. The orientation of the magnetic deflection vector is at an angle of $\sim 36^{\circ}$ to the DMSP trajectory. The orientations of the magnetic deflection vector and the twocell aurora have a $4^{\circ}$ difference.

From the four events we have shown, it is found that there is an angular difference between the orientations of the magnetic deflection vector and the two-cell aurora. We also calculated the angular difference for the other five events. The results have been summarized in Table $1 . \phi_{m}\left(\phi_{t}\right)$ represents the orientation of the magnetic deflection vector (the two-cell aurora) to the DMSP trajectory. The $\phi_{t}$ is $46 \pm 4^{\circ}$ during the substorm growth phase, and $45 \pm 3^{\circ}$ during the substorm expansion phase. Since the difference of the two means is less than the uncertainties of the means, it indicates that the substorm expansion onset does not significantly change the orientation of the two-cell aurora. However, the $\phi_{m}$ is $73 \pm 1^{\circ}$ during the substorm growth phase, and $44 \pm 6^{\circ}$ during the substorm expansion phase, indicating that the substorm expansion onset changes the orientation of the magnetic deflection vector. The angular difference $\left(\left|\phi_{m}-\phi_{t}\right|\right)$ is $28 \pm 5^{\circ}$ during the substorm expansion, and $13 \pm 6^{\circ}$ during the substorm expansion phase. The change in the angular difference from the growth phase to the expansion phase is significant because this change is larger than the uncertainties of the two angular differences. Note that the uncertainty of any parameter used in this study was calculated by the standard deviation of the mean.

\section{Discussion}

In this study we investigate ionospheric characteristics of the two-cell aurora using multiple observations. The two-cell aurora is referred to as a special auroral form identified from Polar UVI auroral images. The two-cell aurora is related to discrete particle precipitation structures near the poleward edge of the auroral oval. Thus, the two-cell aurora is narrower in latitude than the auroral oval. We believe that none of the Polar UVI auroral images can provide a pretty good outline of the auroral oval, due to the problem of sensitivity for auroral emissions. The best way to define the auroral oval is based on particle precipitation. 
a) Polar UVI
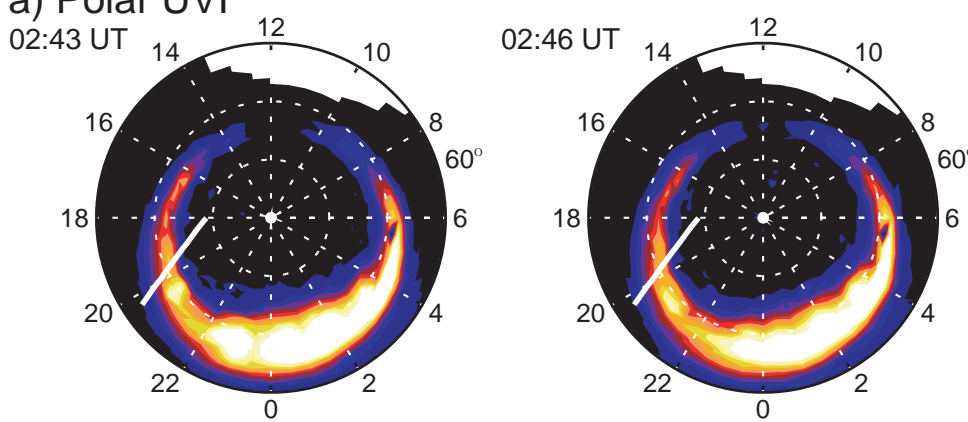

Photons $\mathrm{cm}^{-2} \mathrm{~s}^{-1}$

b) DMSP SSIES and SSM

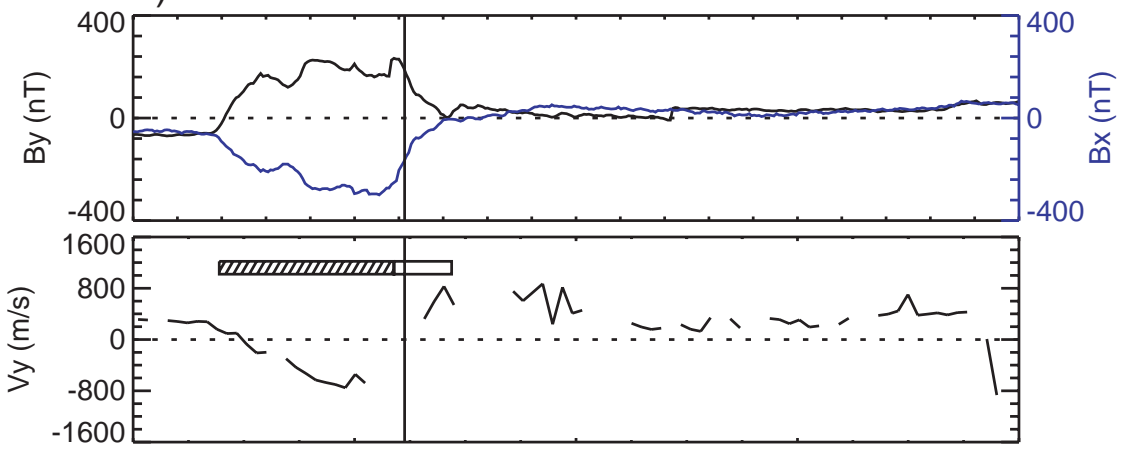

\section{F12 c) DMSP SSJ4}

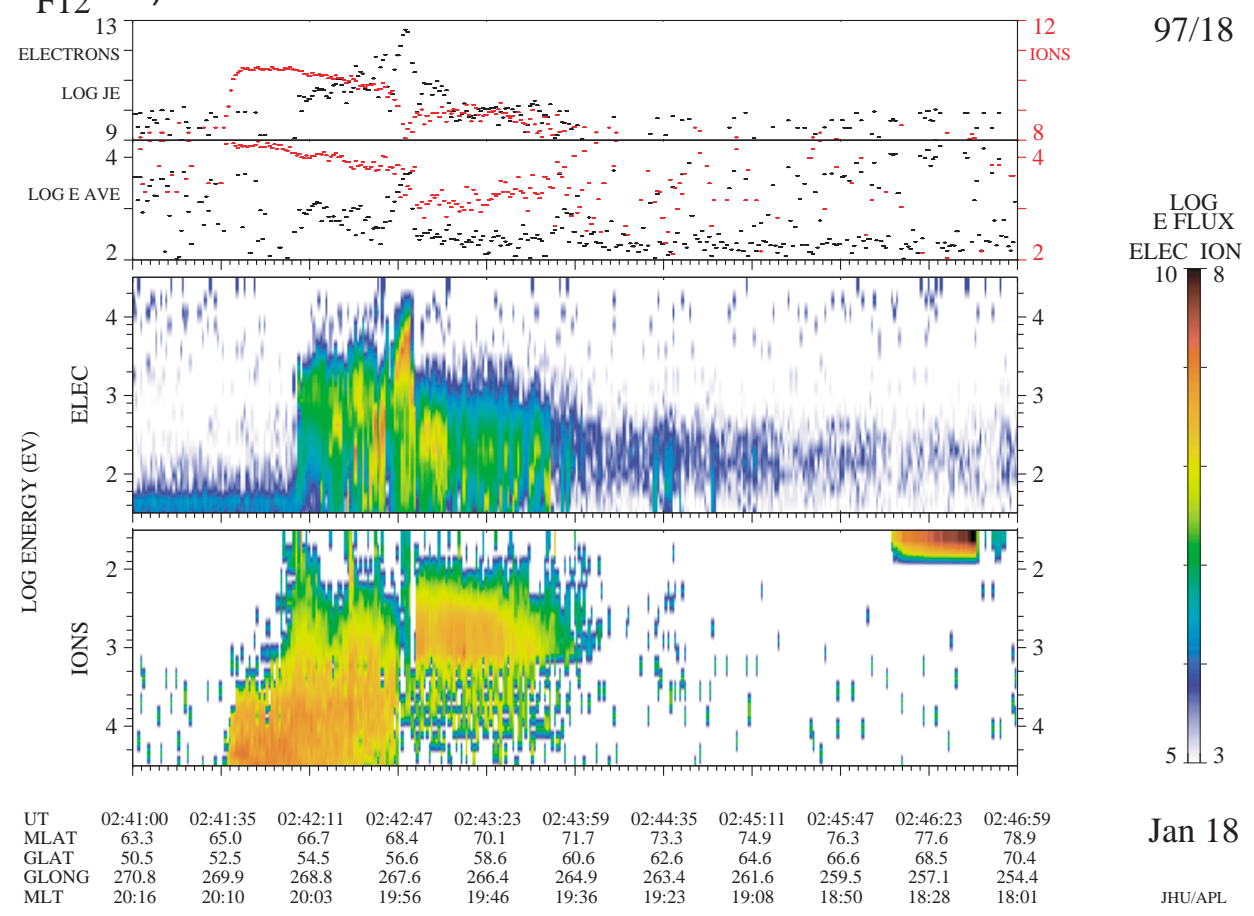

Fig. 5. A summary of observations for the 02:41-02:47 UT, 18 January 1997 event. The format is the same as that for Fig. 2.

The discrete auroral arcs are embedded in the auroral oval. There are often several discrete arcs ( 1 to $10 \mathrm{~km}$ in latitudinal width) which occurred within the region 1 (100 to $400 \mathrm{~km}$ in latitudinal width) portion of the auroral oval. The discrete arcs are commonly shown in a form of sheets which bend and twist into shapes that locally are significantly not aligned with the auroral oval. 
The large-scale region 1 field-aligned current sheet is assumed to be aligned with the auroral oval. The assumption of "infinite current sheets" has been found to be quite good if the length to the end of the current sheet or the radius of the curvature of the current is 5 times greater than the width of the current sheet. The most common locations where the assumption breaks down are the noon and midnight sectors of the auroral zones.

Small-scale field-aligned currents are usually embedded in the large-scale region 1 field-aligned current. The smallscale field-aligned currents may not be exactly aligned with the large-scale region 1 field-aligned current. It is likely that the small-scale field-aligned currents are roughly aligned with visible auroral arcs. Thus, it is possible that these auroral arcs are not aligned with the auroral oval.

We have found that the orientations of the magnetic deflection vector and the two-cell aurora are misaligned. If there is no variation in the field-aligned current or in the ionospheric conductivity with respect to local time, the magnetic deflection vector must be parallel to the current sheet and the two-cell aurora. However, there are conductivity gradients, especially along the terminator. The current system can be changed by these gradients (Burke et al., 1994). If there are gradients in the strength of the field-aligned currents and/or in the conductivity in the auroral oval, as a function of local time, it is more likely that the magnetic deflection vector will not be aligned with the current sheet and the two-cell aurora.

We have also found that the orientation of the magnetic deflection vector produced by the region 1 field-aligned current changed from the growth phase to the substorm expansion phase. We believe that the local time distributions of the field-aligned currents and conductivity gradients are important keys to the understand physical processes underlying the change in the magnetic deflection vector from the growth phase to the substorm expansion phase. However, we have no data for the local time distributions of the field-aligned currents and conductivity gradients for these events, to evaluate this aspect.

From this study it is found that the uncertainty of the orientation of the magnetic deflection vector during the substorm expansion phase is larger than that during the substorm growth phase. Loops and surges at the auroral region in the evening sector during the expansion phase may add more variations to the orientation of the magnetic deflection vector. Moreover, the magnetic deflection vector is also influenced by the region 2 field-aligned current, even if DMSP is crossing field lines threaded by the region 1 field-aligned current. Enhanced region 2 field-aligned current during the substorm expansion may alter the orientation of the magnetic deflection vector.

An important result of this study is that there is a change in the orientation of the magnetic deflection vector in a transition from the substorm growth phase to the expansion phase. One may question how long before the expansion onset, or into the expansion phase, had the activity proceeded at the time of the DMSP pass. To address this concern, we also calculated the timing of the DMSP pass away from the sub- storm expansion onset $\left(T_{a}\right)$ for each of the nine events, as listed Table 1. A negative (positive) sign in $T_{a}$ denotes that the DMSP pass occurred before (after) the substorm expansion onset. A comparison of $\phi_{m}$ to $T_{a}$ has shown that the orientation of the magnetic deflection vector is independent of the timing of the DMSP pass away from the substorm expansion onset.

We cannot determine whether the two-cell aurora is discrete or diffuse from Polar UVI auroral images alone. DMSP particle precipitation data have shown one or several discrete electron structures associated with the dusk-side branch of the two-cell aurora. This result is consistent with the one obtained by Winningham et al. (1979), who studied particle precipitation and magnetometer data for the evening sector and found that discrete particle structures, which are associated with the boundary plasma sheet, appeared at the poleward edge of the eastward electrojet.

Lyons et al. (2002) studied the pre-onset and expansionphase auroral arcs using the Canadian Auroral Network for the Open Program Unified Study (CANOPUS) meridianscanning photometer and all-sky imager observations. They found that one or more arcs are seen across the sky throughout the growth phase prior to the substorm expansion onset. This result supports our results that one or several precipitation regions are associated with the dusk-side branch of the two-cell aurora. They also found that the auroral breakup often occurs along a thin arc that forms equatorward of all growth phase arcs a few minutes prior to the onset, revealing the importance of a study of growth phase auroras, in order to understand substorm expansion onsets.

Shue et al. (2002) did not examine any convection data before they named the aurora the two-cell aurora. In this study, we actually examined DMSP ion drift meter data and confirmed that the convection was anti-sunward in the polar cap and was returned sunward at lower latitudes on the dusk. This convection feature is consistent with the dusk-side portion of the typical two-cell convection pattern. Note that satellite observations (e.g. Heppner and Maynard 1987) and many radar observations showed that sunward convection exists all the time, even under northward IMF in the auroral zone and anti-sunward convection "just" poleward of it. One may think that our statement above is not completely justified. However, the DMSP ion drift meter data show the antisunward convection "not just" poleward of the sunward convection, but extending deep in the polar cap. We also examined convection maps on Super Dual Auroral Radar Network (SuperDARN) data. We found that all of the maps showed a two-cell convection pattern, but none of them had sufficient data coverage. Therefore, all the SuperDARN patterns are most likely produced by an empirical model, which is based on the IMF $B_{y} / B_{z}$.

\section{Conclusions}

In this study we utilize Polar UVI auroral images and DMSP particle precipitation, convection, magnetic field data, to 
investigate characteristics of the dusk-side branch of the twocell aurora. A portion of our results derived from this study confirm the previous ones, but we have the following new findings:

1. The average angle between the orientation of the twocell aurora and the DMSP trajectory line is $46 \pm 4^{\circ}$ $\left(45 \pm 3^{\circ}\right)$ during the substorm growth (expansion) phase. This indicates that the substorm expansion onset does not significantly change the orientation of the dusk-side branch of the two-cell aurora.

2. A change in the orientation of the magnetic deflection vector associated with the dusk-side branch of the twocell aurora occurred in a transition from the growth phase to the substorm expansion phase. The orientation of the magnetic deflection vector with respect to the DMSP trajectory is $73 \pm 1^{\circ}$ during the substorm growth phase, and $44 \pm 6^{\circ}$ during the substorm expansion phase.

3. The angular difference between the orientation of the magnetic deflection vector and the orientation of the two-cell aurora is $28 \pm 5^{\circ}$ during the substorm growth phase, and $13 \pm 6^{\circ}$ during the substorm expansion phase.

Acknowledgements. This work was supported in part by National Science Council grant NSC-93-2111-M-008-010 and National Space Organization grant 94-NSPO(B)-SP-FA07-02 to National Central University, and in part by National Science Foundation grant ATM-0001621 to The Johns Hopkins University Applied Physics Laboratory. We thank G. K. Parks for providing us with Polar auroral images. We also thank A. J. Lazarus for the use of Wind plasma data, and R. P. Lepping for the use of Wind magnetic field data.

The Editor in Chief thanks N. Nishitani and another referee for their help in evaluating this paper.

\section{References}

Baker, J. B., Clauer, C. R., Ridley, A. J., Papitashvili, V. O., Brittnacher, M. J., and Newell, P. T.: The nightside poleward boundary of the auroral oval as seen by DMSP and the Ultraviolet Imager, J. Geophys. Res., 105, 21 267-21 280, 2000.

Baker, K. B. and Wing, S.: A new magnetic coordinate system for conjugate studies at high latitudes, J. Geophys. Res., 94, 91399143, 1989.

Brittnacher, M., Elsen, R., Parks, G., Chen, L., Germany, G., and Spann, J.: A dayside auroral energy deposition case study using the Polar Ultraviolet Imager, Geophys. Res. Lett., 24, 991-994, 1997.

Brittnacher, M., Fillingim, M., Parks, G., Germany, G., and Spann, J.: Polar cap area and boundary motion during substorms, J. Geophys. Res., 104, 12 251-12 262, 1999.

Burke, W. J., Machuzak, J. S., Maynard, N. C., Basinska, E. M., Erickson, G. M., Hoffman, R. A., Slavin, J. A., and Hanson, W. B.: Auroral ionospheric signatures of the plasma sheet boundary in the evening sector, J. Geophys. Res., 99, 2489-2499, 1994.

Carbary, J. F., Sotirelis, T., Newell, P. T., and Meng, C.-I.: Auroral boundary correlations between UVI and DMSP, J. Geophys. Res., 108, 1018, doi:10.1029/2002JA009378, 2003.
Clauer, C. R.and Kamide, Y.: DP 1 and DP 2 current systems for the March 22, 1979 substorms, J. Geophys. Res., 90, 1343-1354, 1985.

Dungey, J. W.: Interplanetary magnetic field and auroral zones, Phys. Rev. Lett., 6, 47-49, 1961.

Germany, G. A., Torr, M. R., Torr, D. G., and Richards, P. G.: Use of FUV auroral emissions as diagnostic indicators, J. Geophys. Res., 99, 383-388, 1994.

Hardy, D. A., Schmitt, L. K., Gussenhoven, M. S., Marshall, F. J., Yeh, H. C., Schumaker, T. L., Huber A., and J. Pantazis: Precipitating electron and ion detectors (SSJ/4) for the block 5D/flights 6-10 DMSP satellites: Calibration and data presentation, Rep. AFGL-TR-84-0317, Air Force Geophys. Lab., Hanscom Air Force Base, MA, 1984.

Heelis, R. A., Winningham, J. D., Hanson, W. B., and Burch, J. L.: The relationships between high-latitude convection reversals and the energetic particle morphology observed by Atmosphere Explorer, J. Geophys. Res., 85, 3315-3324, 1980.

Heppner, J. P. and Maynard, N. C.: Empirical high-latitude electric field models, J. Geophys. Res., 92, 4467-4489, 1987.

Iijima, T. and Potemra, T. A.: The amplitude distribution of fieldaligned currents at northern high latitudes observed by Triad, J. Geophys. Res., 81, 2165-2174, 1976.

Kamide, Y.: The two-component auroral electrojet, Geophys. Res. Lett., 9, 1175-1178, 1982.

Kamide, Y. and Kokubun, S.: Two-component auroral electrojet: Importance for substorm studies, J. Geophys. Res., 101, 13027 $13046,1996$.

Kauristie, K., Weygand, J., Pulkkinen, T. I., Murphree, J. S., and Newell, P. T.: Size of the auroral oval: UV ovals and precipitation boundaries compared, J. Geophys. Res., 104, 2321-2331, 1999.

Lin, C. S. and Hoffman, R. A.: Characteristics of the inverted V event, J. Geophys. Res., 84, 1514-1524, 1979.

Liou, K., Newell, P. T., Meng, C.-I., Brittnacher, M., and Parks, G.: Characteristics of the solar wind controlled auroral emissions, J. Geophys. Res., 103, 17 543-17 557, 1998.

Lyons, L. R., Voronkov, I. O., Donovan, E. F., and Zesta, E., Relation of substorm breakup arc to other growth-phase auroral arcs: J. Geophys. Res., 107, 1390, doi:10.1029/2002JA009317, 2002.

Marklund, G. T., Blomberg, L. G., Stasiewicz, K., Murphree, J. S., Pottelette, R., Zanetti, L. J., Potemra, T. A., Hardy, D. A., and Rich, F. J.: Snapshots of high-latitude electrodynamics using Viking and DMSP F7 observations, J. Geophys. Res., 93, 14 479-14 492, 1988.

Meng, C.-I.: Electron precipitations and polar auroras, Space Sci. Rev., 22, 223-300, 1978.

Newell, P. T., Lyons, K. M., and Meng, C.-I.: A large survey of electron acceleration events, J. Geophys. Res., 101, 2599-2614, 1996.

Nishida, A.: Geomagnetic DP 2 fluctuations and associated magnetospheric phenomena, J. Geophys. Res., 73, 1795-1803, 1968.

Rich, F. J. and Hairston, M. R.: Large-scale convection patterns observed by DMSP, J. Geophys. Res., 99, 3827-3844, 1994.

Rich, F. J., Hardy, D. A., and Gussenhoven, M. S.: Enhanced ionosphere-magnetosphere data from the DMSP satellites, Eos Trans. AGU, 66, 513-516, 1985.

Shue, J.-H. and Weimer, D. R.: The relationship between ionospheric convection and magnetic activity, J. Geophys. Res., 99, 401-415, 1994.

Shue, J.-H., Kamide, Y., Elphinstone, R. D., and Nishitani, N.: Intense growth phase events of substorms, J. Geophys. Res., 105, 5357-5371, 2000. 
Shue, J.-H., Newell, P. T., Liou, K., and Meng, C.-I.: Influence of interplanetary magnetic field on global auroral patterns, J. Geophys. Res., 106, 5913-5926, 2001.

Shue, J.-H., Newell, P. T., Liou, K., Meng, C.-I., Kamide, Y., and Lepping, R. P.: Two-component auroras, Geophys. Res. Lett., 29, doi:10.1029/2002GL014657, 2002.

Smiddy, M., Burke, W. J., Kelley, M. C., Saflekos, N. A., Gussenhoven, M. S., Hardy, D. A., and Rich, F. J.: Effects of highlatitude conductivity on observed convection electric fields and Birkeland currents, J. Geophys. Res., 85, 6811-6818, 1980.

Strickland, D. J., Daniel Jr., R. E., Jasperse, J. R., and Basu, B.: Transport-theoretic model for the electron-proton-hydrogen atom aurora, 2. Model results, J. Geophys. Res., 98, $21533-$ $21548,1993$.
Torr, M. R., Torr, D. G., Zukic, M., et al.: A far ultraviolet imager for the international solar-terrestrial physics mission, Space Sci. Rev., 71, 329-383, 1995.

Winningham, J. D., Kawasaki, K., and Rostoker, G.: Energetic particle precipitation into the high-latitude ionosphere and the auroral electrojets, 1. Definition of electrojet boundaries using energetic electron spectra and ground-based magnetometer data, J. Geophys. Res., 84, 1993-2005, 1979. 